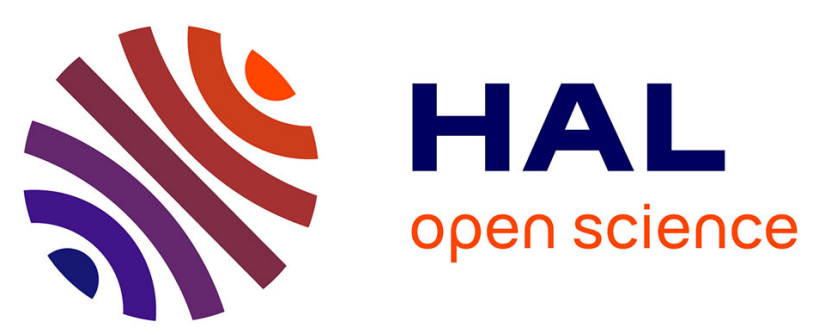

\title{
CALCULATION OF DEFECT ENTROPIES IN IONIC CRYSTALS IN THE QUASIHARMONIC APPROXIMATION : APPLICATION TO FLUORITES
}

P. Jacobs, M. Nerenberg, J. Govindarajan, T. Haridasan

\section{- To cite this version:}

P. Jacobs, M. Nerenberg, J. Govindarajan, T. Haridasan. CALCULATION OF DEFECT ENTROPIES IN IONIC CRYSTALS IN THE QUASIHARMONIC APPROXIMATION: APPLICATION TO FLUORITES. Journal de Physique Colloques, 1981, 42 (C6), pp.C6-914-C6-916. 10.1051/jphyscol:19816272 . jpa-00221365

HAL Id: jpa-00221365 https://hal.science/jpa-00221365

Submitted on 1 Jan 1981

HAL is a multi-disciplinary open access archive for the deposit and dissemination of scientific research documents, whether they are published or not. The documents may come from teaching and research institutions in France or abroad, or from public or private research centers.
L'archive ouverte pluridisciplinaire HAL, est destinée au dépôt et à la diffusion de documents scientifiques de niveau recherche, publiés ou non, émanant des établissements d'enseignement et de recherche français ou étrangers, des laboratoires publics ou privés. 


\author{
P.W.M. Jacobs, M.A.H. Nerenberg, J. Govindarajan and T.M. Haridasan \\ University of Western Ontario, London, Ontario, Canada N6A $5 B 7$
}

1. Outline of Theory The dynamical matrix for a crystal containing an interstitial can be written in the form

$$
\overline{\mathrm{L}}=\left|\begin{array}{ccc}
\mathrm{L} & -\delta \mathrm{L} & \mathrm{A} \\
\mathrm{A}^{\mathrm{T}} & \Lambda
\end{array}\right|
$$

where $L$ is the dynamical matrix of the perfect crystal, $\Lambda$ is that part of $L$ that refers exclusively to the interstitial and $A$ is the matrix that connects the interstitial coordinates with those of the rest of the lattice. $A^{T}$ is the transpose of A. $\delta I$ is the matrix that describes the force constant changes which occur because of the relaxations of the lattice ions due to the presence of the interstitial. The Green matrix $\overline{\mathrm{G}}=\overline{\mathrm{L}}^{-1}$ may also be written in partitioned form like that in (1), whence it may be shown that the determinant of $\bar{G}$ is

$$
|\bar{G}|=\left|I-G \delta L^{\prime} \| G\right||\Lambda|^{-1}
$$

where $\delta L^{\prime}=\delta L+A \Lambda^{-1} A^{T}$ and $I$ is the $3 N \times 3 N$ unit matrix, $N$ being the number of atoms in the crystal. Since static lattice calculations show that relaxations of the lattice ions are small except for the first and second neighbours, the non-zero elements of $\delta \mathrm{L}$ will be restricted to a small sub-space comprising these $\mathrm{n}$ ions that are perturbed appreciably by the interstitial. It then follows that

$$
\left|I-G \delta L^{\prime}\right|=|I-g \delta \ell '|
$$

where $I$ on the $R S$ of (3) is now the $3 n \times 3 n$ unit matrix.

$$
\delta \ell^{\prime}=\delta \ell+\Lambda^{-1} a^{T}
$$

where

$$
A=\left|\begin{array}{l}
0 \\
a
\end{array}\right|
$$

and the dimensions of the matrix a are $3 \mathrm{n} \times 3$.

The entropy change associated with the introduction of an anion from $\infty$ into an interstitial position in the high-temperature approximation may then be written in the form

$$
s_{i}=-\frac{1}{2} k \ln \lim _{\omega \rightarrow 0}\left|I-g \delta \ell^{r}\right|+3 k\left\{1-\ln \left(h \omega_{I} / k T\right)\right\}
$$

where $\omega_{I}$ is the hypothetical frequency of vibration of an interstitial in a lattice in which all the host-lattice ions are frozen at their (perfect lattice) equilibrium positions. In similar fashion the dynamical matrix of a crystal with a vacancy is

$$
\overline{\mathrm{L}}_{\mathrm{v}}=\mathrm{L}_{\mathbf{t}}-\delta \ell
$$


where $L_{t}$ is the dynamical matrix $L$ of the crystal without a vacancy, truncated by removing the three rows and column belonging to the ion which is no longer present. $\delta l$ is the matrix of force constant changed due to the relaxations of the ions caused by the vacancy. It includes as well the changes in the "self-terms" of the fons because of the removal from these sums the contributions due to the ion which has now been removed. By partitioning $\overrightarrow{\mathrm{L}}_{v}$, and also the perfect crystal dynamical matrix $L$, Into blocks such that one of the diagonal blocks of $\overline{\mathrm{L}}_{\mathrm{v}}$ represents the 'defect space' (that is those ions that are perturbed by the presence of the vacancy - in practice this means its first and second neighbours) and the corresponding block of $L$ represents the defect space-to-be (including the fon that will become a vacancy) it may be shown that the entropy change associated with the removal of a lattice anion to $\infty$ is

$$
s_{v}=-\frac{3}{2} k \ln \lim _{\omega \rightarrow 0}\left\{m_{-}^{3}\left|g_{v}\right|\left|\left(g_{v}^{-1}\right)_{t}-\delta \ell\right|(k T / h)^{6}\right\}-3 k
$$

The entropy of formation of a Frenkel defect is thus given by

$$
\begin{aligned}
s_{F} & =s_{1}+s_{v} \\
& =-\frac{1}{2} k \ln \lim _{\omega \rightarrow 0}\left\{\left|g_{v}\right|\left|\left(g_{v}^{-1}\right)_{t}-\delta l\right|\left|I-g \delta l^{\prime}\right| m_{-}^{3} \omega_{I}^{6}\right\}
\end{aligned}
$$

In these expressions $m_{-}$is the mass of an anion, $g_{v}$ is the perfect-lattice Green matrix for the defect space-to-be and $\left(g_{\mathrm{v}}{ }^{-1}\right)_{t}$ is the truncated version of the reciprocal of $\mathrm{g}_{\mathrm{v}}$ (that $1 \mathrm{~s}$, with the 3 rows and colums deleted that correspond to the ion which is to be removed when the vacancy is found). We may not multiply out the first product of determinants in (9) since the operations of truncation and inversion do not, in general, commute.

2. Calculation The necessary Green functions were evaluated using shell modeI parameters fitted to the experimental phonon dispersion. These parameters were taken from the work of Elcombe and Pryor ${ }^{1}$ and Elcombe ${ }^{2}$. For the calculation of $\delta l$ we require the coordinates of the ions in the imperfect crystal which were obtained from the HADES program. ${ }^{3}$ The changes in the short-range interaction were restricted to second neighbours, but in the calculation of the self-terms in the $\delta l$ matrix, it was necessary to ensure that each ion had its full complement of first and second nefghbours, even though these neighbours might lie outside the defect space. The short-range force constants were calculated using the two-body central potential of Catlow, Norgett and Ross". The change in the coulomb interaction was calculated only between the ion at the origin (which later became the site of the vacancy) and its first and second neighbours (Benedek ${ }^{5}$ ). The defect space comprising the interstitial and its first and second neighbours consisted of 15 ions, but 95 ions had to be taken into account while calculating the diagcnal terms of $\delta l$. The change in the coulomb force between the interstitial and only its first and second neighbours was included. Additionally, the presence of the interstitial is felt through the terms a $\Lambda^{-1} a^{T}$, where $\Lambda^{-1}$ was calculated from the self term of the interstitial. The calculation is a quasiharmonic one in that the actual lattice parameter at each $T$ was used in determining the relaxations of the ions. The Green matrix at, each $T$ was obtained by a scaling procedure ${ }^{6}$. This calculation yields an entropy of 
Frenke1 defect formation at constant volume, $\mathbf{s}_{\mathbf{F}}^{\mathbf{v}}$. For comparison with experiment we need the corresponding entropy at constant pressure $s^{P}$. Since to first order in $v^{p}$, the volume change on forming a Frenkel. defect at constant pressure, the Gibbs energy change $g^{P}$ is equal to the Helmholtz energy change $f^{V}{ }^{7}, s^{P}$ is related to by $s^{V}$ by

$$
s^{p}-s^{v}=-\left(\frac{\partial f^{v}}{\partial v}\right) \beta^{p} v
$$

where $v$ is the volume per molecule $\left(=2 r_{0}^{3}, r_{0}\right.$ being the $F^{-} F^{-}$nn distance) and $\beta^{p}$ the expansivity. Since both the ener $y$ and entropy of defect formation at constant volume $u^{v}$ and $s^{v}$ are determined by our calculations, $f^{v}$ and $s^{p}$ may be found and compared with experimental values.

\section{Results}

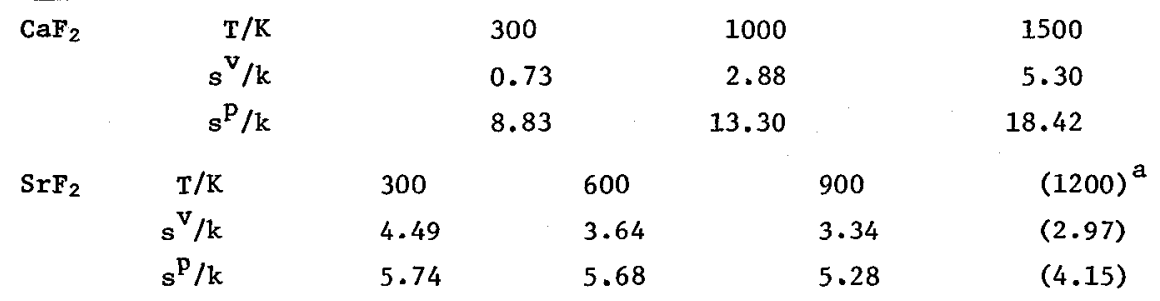

Based on extrapolated values.

For $\mathrm{CaF}_{2}{ }^{8}$ the mean calculated value of $\mathrm{s}^{\mathrm{p}}$ in the range $550-1000 \mathrm{~K}$ is $\sim / 0 \mathrm{k}$, and the experimental value of $\mathrm{s}^{\mathrm{p}}$ is about $5 \mathrm{k} \cdot{ }^{8}$ For $\operatorname{SrF}_{2} \mathrm{~s}^{\mathrm{p}}$ (expt) $=4.1 \mathrm{k}$ in the range $\sim 570-1100 \mathrm{~K}$, and the calculated value of $\mathrm{s}^{\mathrm{p}}$ is about $5 \mathrm{k}$. The quasiharmonic calculation depends critically on a knowledge of the temperature dependence of the lattice constant.

Acknowledgement: We acknowledge support of this research by the Natural Sciences and Engineering Research Council of Canada. T.M.H. is grateful to the Centre for Inter-disciplinary studies in Chemical Physics for the award of a Fellowship and for further financial support, and to Madurai Kamaraj University for leave of absence. We are most grateful to Dr. A.B. Lidiard and Dr. M. Hutchings for data on the lattice constant of $\mathrm{CaF}_{2}$.

\section{References}

1. Elcombe M.M. and Pryor A.W., J.Phys. C (Solid State) $\underline{3}, 492$ (1970).

2. Elcombe M.M., J.Phys. C (Solid State) $\underline{5}, 2702$ (1972).

3. Norgett M.J., AERE Harwel1 Report R 7650 (1974).

4. Catlow C.R.A., Norgett M.J. and Ross T.A., J.Phys. C 10, 1627 (1977).

5. Benedek G., Physics of Impurity Centres in Crystals (Tallinn), P.182 (19.72).

6. Haridasan T.M., Govindarajan J., Nerenberg M.A.H. and Jacobs P.W.M., J.Phys. C 12, 5371 (1979).

7. Gillan M.J., Phil. Mag 43A, 301 (1981).

8. Ong S.H. and Jacobs P.W.M., J.Phys. (Paris) 37, C7-331 (1976).

9. Jacobs P.W.M. and Ong S.H., in course of publication. 